\title{
56. WHOLE-ROCK CHEMISTRY OF IGNEOUS ROCKS FROM DSDP LEG 37
}

D.F. Strong and Rebecca Jamieson, Department of Geology, Memorial University of Newfoundland, St. John's, Newfoundland

Fifty-three whole-rock samples from Holes 332A, 332B, 333A and Sites 334 and 335 were analyzed for major elements (by atomic absorption), loss on ignition, and trace elements (by X-ray fluorescence). They represent the full depth range and most rock types from each hole, with the majority of samples from Hole 332B. With the exception of two harzburgites, all rocks are typical oceanic tholeiites (Figures 1 and 2), and the range of composition is comparable to that found for mid-ocean ridge basalts in general (Figures 3 and 4 ).

The compositional variation (e.g., Figure 5) is explicable by fractionation of dominantly olivine, clinopyroxene, and plagioclase. Comparison with experimentally determined phase relations, e.g., Figures 6 and 7 , indicates that such fractionation took place under low-pressure conditions, with noncumulate samples approximating the one-atmosphere cotectics for these phases. The harzburgites cannot be related to the mafic rocks by crystal fractionation, at least at low pressures, and might be explained as residual upper mantle depleted by partial melting.

There is little vertical variation in composition, except for the depth range between 200 and 300 meters in Hole 332B, where there appears to be a cyclic variation in mafic associated elements, best shown by $\mathrm{Cr}$ and $\mathrm{Ni}$ (Figure 8). This obviously relates to fractionation of mafic phases, and the presence of sedimentary units

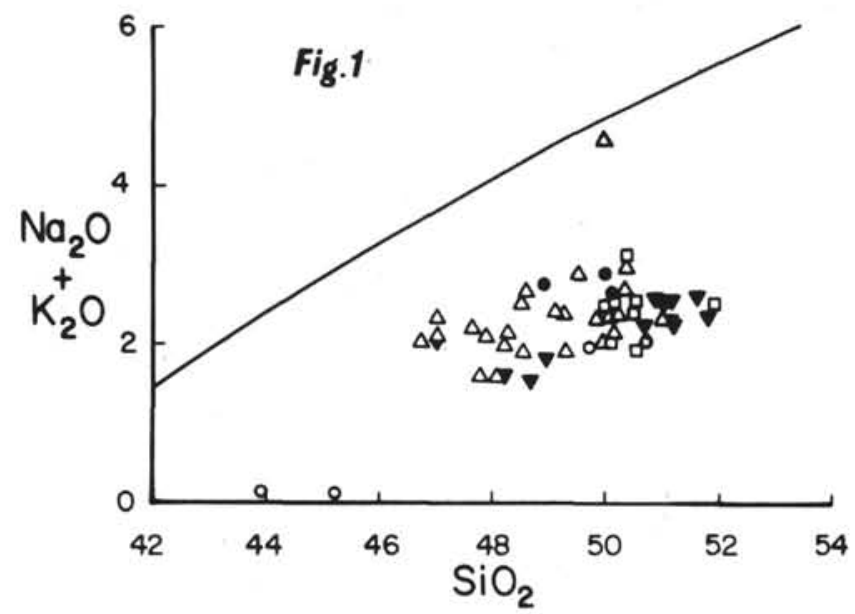

Figure 1. Alkali silica diagram for Leg 37 basalts.Symbols for this and subsequent figures designate samples from different holes as follows: squares - Hole 333A; dots Site 335; circles - Site 334; open triangles - Hole 332B; solid triangles - Hole 332A. The line is that of Irvine and Baragar (1972) separating alkaline from subalkaline (tholeiitic) rocks.

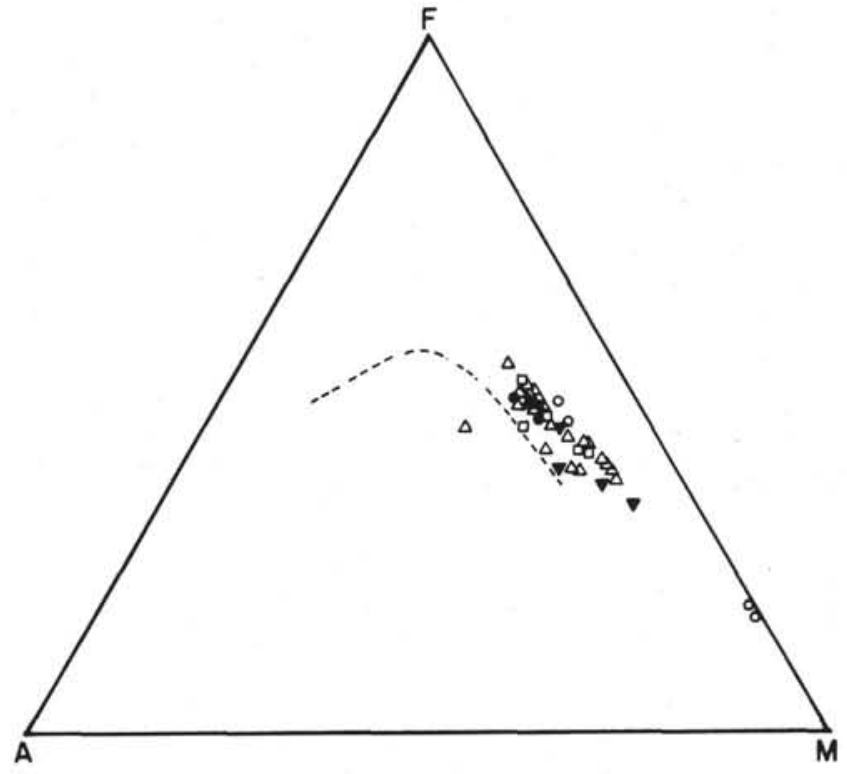

Figure 2. $\mathrm{A}\left(\mathrm{Na}_{2} \mathrm{O}+\mathrm{K}_{2} \mathrm{O}\right): \mathrm{F}$ (total iron as $\left.\mathrm{FeO}\right): \mathrm{M}$ $(\mathrm{MgO})$ diagram for Leg 37 basalts. Dashed line is that of Irvine and Baragar (1972) separating (above) alkaline basalts from subalkaline basalts.

within these cycles suggest that the higher concentrations are at the top of the cyclic units and that crystal accumulation took place in magma chambers before eruption.

\section{REFERENCES}

Clarke, D.B., 1970. Tertiary basalts of Baffin Bay: possible primary magma from the mantle: Contrib. Mineral. Petrol., v 25, p. 203-224.

Irvine, T.N. and Baragar, W.R.A., 1972. A guide to the chemical classification of the common volcanic rocks: Canadian J. Earth Sci., v. 8, p. 523-548.

Kay, R., Hubbard, N.J., and Gast, P.W., 1970. Chemical characteristics and origin of oceanic ridge volcanic rocks: J. Geophys. Res., v. 75, p. 1585-1613.

O'Hara, M.J., 1968. The bearing of phase equilibria studies in synthetic and natural systems on the origin and evolution of basic and ultrabasic rocks: Earth Sci. Rev., v. 4, p. 236245.

Pearce, J.A. and Cann, J.R., 1971. Ophiolite origin investigated by discriminant analysis using $\mathrm{Ti}, \mathrm{Zr}$ and $\mathrm{Y}$. Earth Planet. Sci. Lett., v. 12, p. 339-349.

Tilley, C.E. and Yoder, H.S., 1964. Pyroxene fractionation in mafic magma at high pressures and its bearing on basalt genesis. Carnegie Inst. Wash. Yearbook, v. 63, p. 114-121.

Tilley, C.E., Yoder, H.S., and Schairer, J.F., 1963. Melting relations of basalts: Carnegie Inst. Wash. Yearbook, v. 62, p. 77-84. 


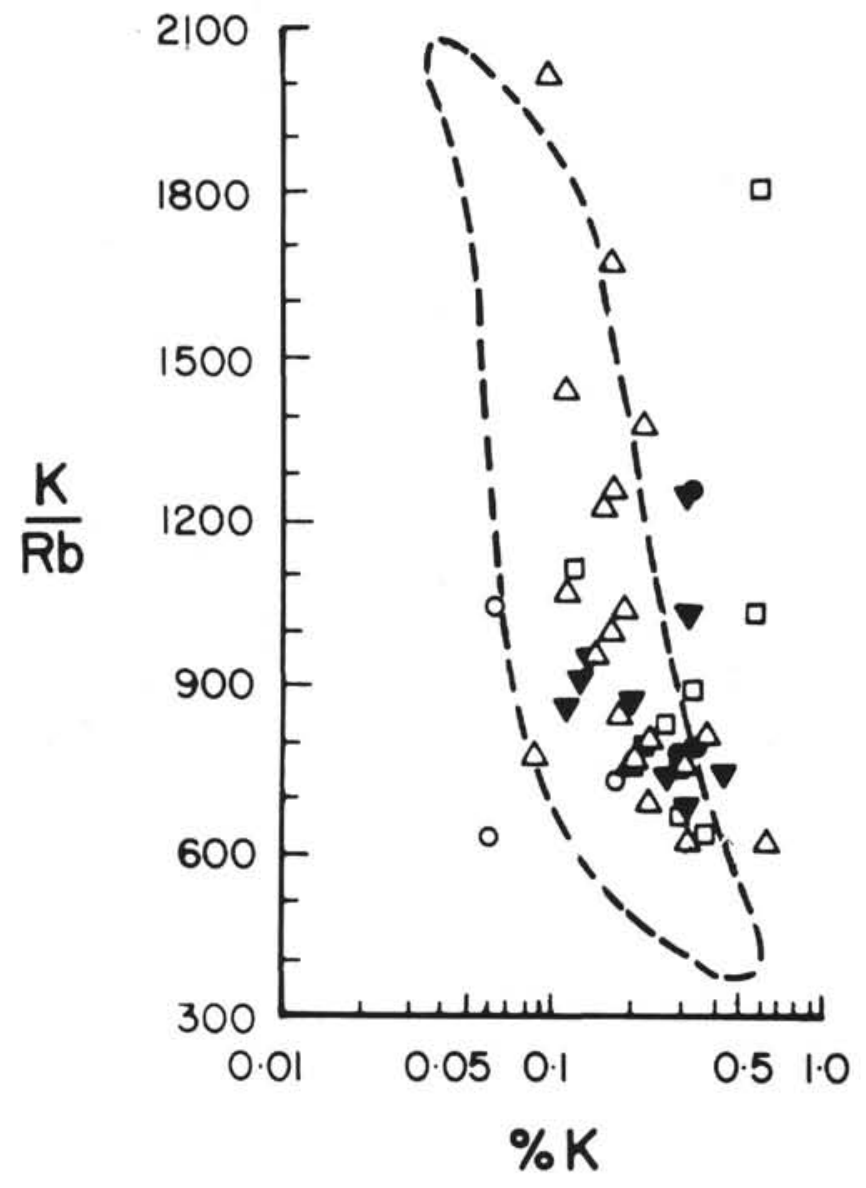

Figure 3. $K / R b$ versus $K$ in Leg 37 basalts. Dashed line is that of Kay et al. (1970) enclosing most of the midocean ridge tholeiites discussed by them.

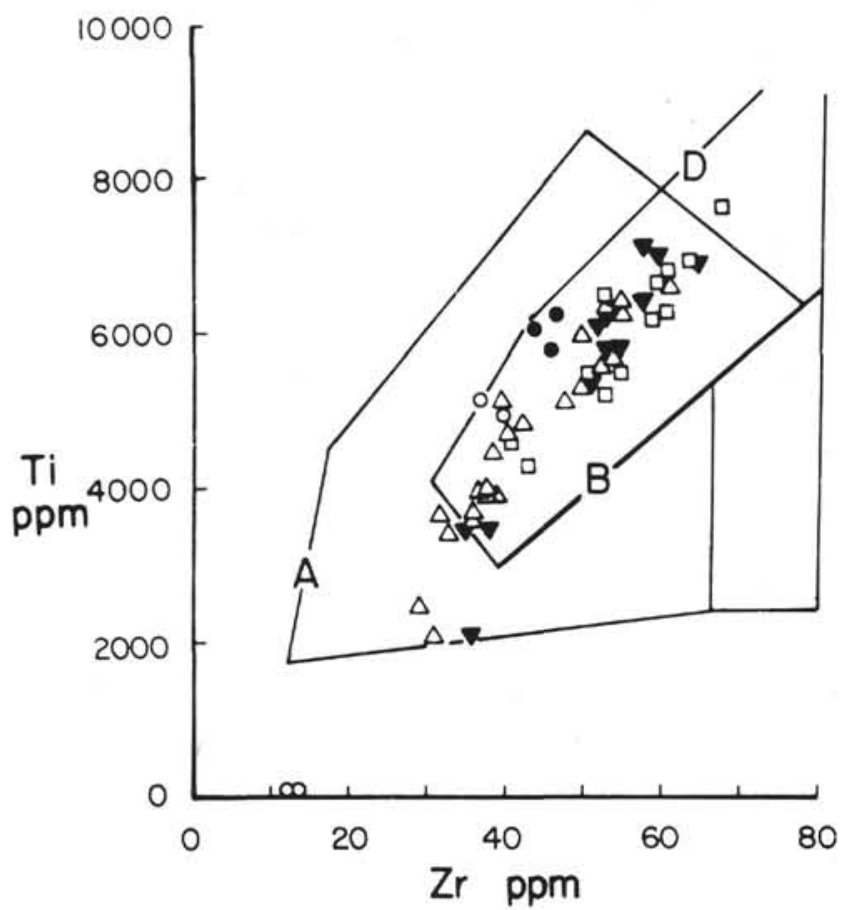

Figure 4. $\mathrm{Ti}$ versus $\mathrm{Zr}$ diagram for Leg 37 basalts. Lines drawn after Pearce and Cann (1971) outlining fields of low- $K$ island arc basalts $(A)$, oceanic tholeiites $(D)$, and field of overlap (B). Note that the Leg 37 basalts are lower in $\mathrm{Ti}$ and $\mathrm{Zr}$ than many oceanic tholeiites.

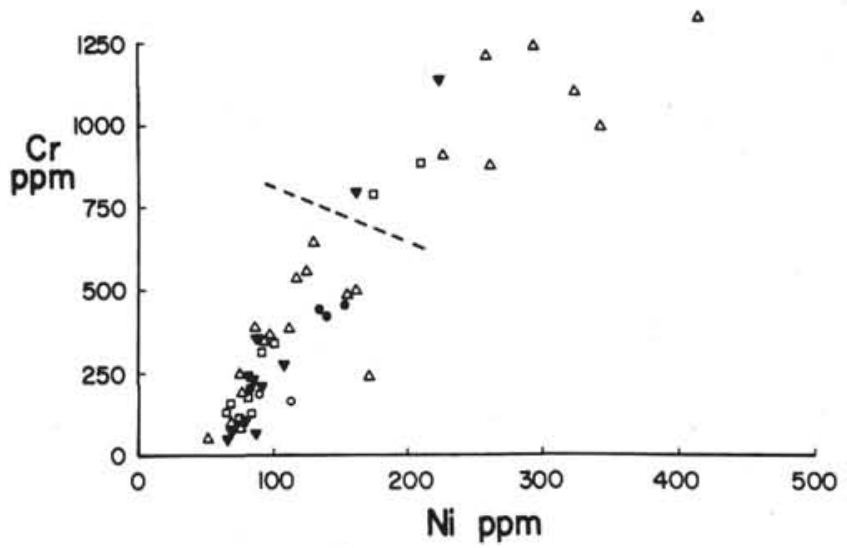

Figure 5. Cr versus $\mathrm{Ni}$ in Leg 37 basalts. Those above the dashed line plot in the primary phase volume of olivine in Figures 6 and 7, i.e., the high $\mathrm{Cr}$ and Ni reflect olivine accumulation. 


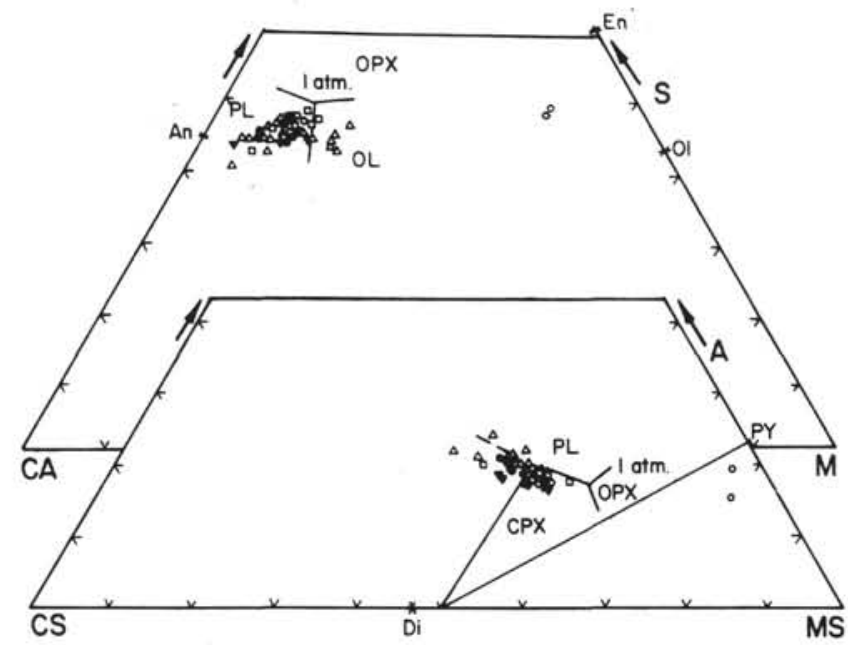

Figure 6. Projections of Leg 37 basalts in the CMAS tetrahedron of O'Hara (1968). (A) Projection from diopside in the CA-M-S plane with one-atmosphere cotectics drawn from the data used by O'Hara (1968). This projection is used instead of the $C_{3} A-M-S$ plane used by $O$ 'Hara because it introduces less distortion in the distribution of data points. Note the dominant effects of plagioclase and olivine accumulation on compositions in the projection. (B) Projection from olivine in the CS$M S$-A plane with one-atmosphere cotectics after O'Hara (1968). Note the correspondence to the o1-cpx-plag cotectic, except for slight cpx accumulation. Note that no samples plot within the opx field, except for the two harzburgites (open circles) from Site 334.

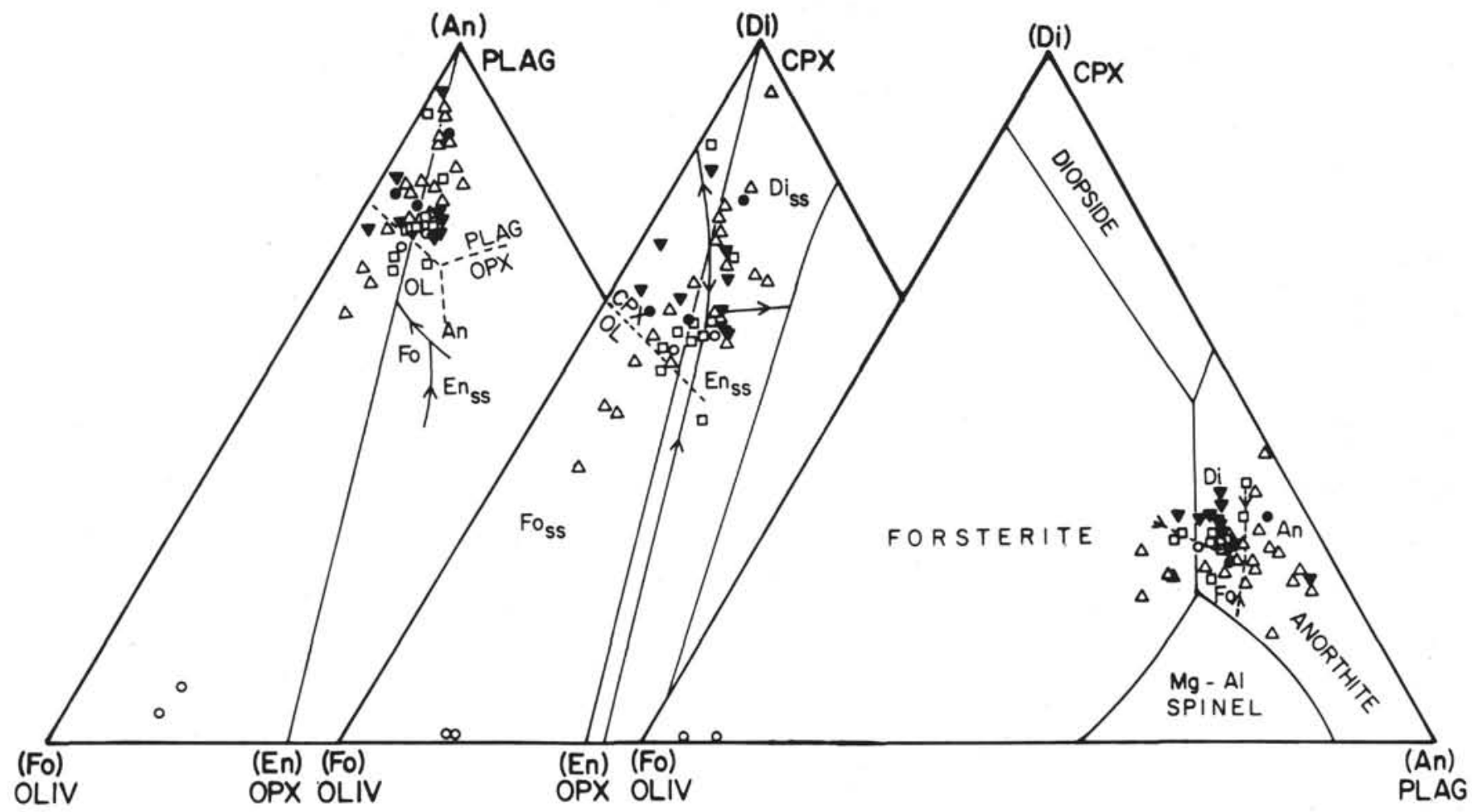

Figure 7. Projections of Leg 37 basalts into the normativebasalt tetrahedron, with cotectics for synthetic.(solid) and natural (dashed) compositions as drawn by Clarke (1970), except for the Fo-An-Di plane where the dashed cotectic for natural compositions was drawn from the data of Tilley and Yoder (1964) and Tilley et al. (1963). All projections show a close correspondence between "natural" cotectics and Leg 37 basalts. Those which fall off the cotectics reflect the compositional effects of crystal accumulation. 


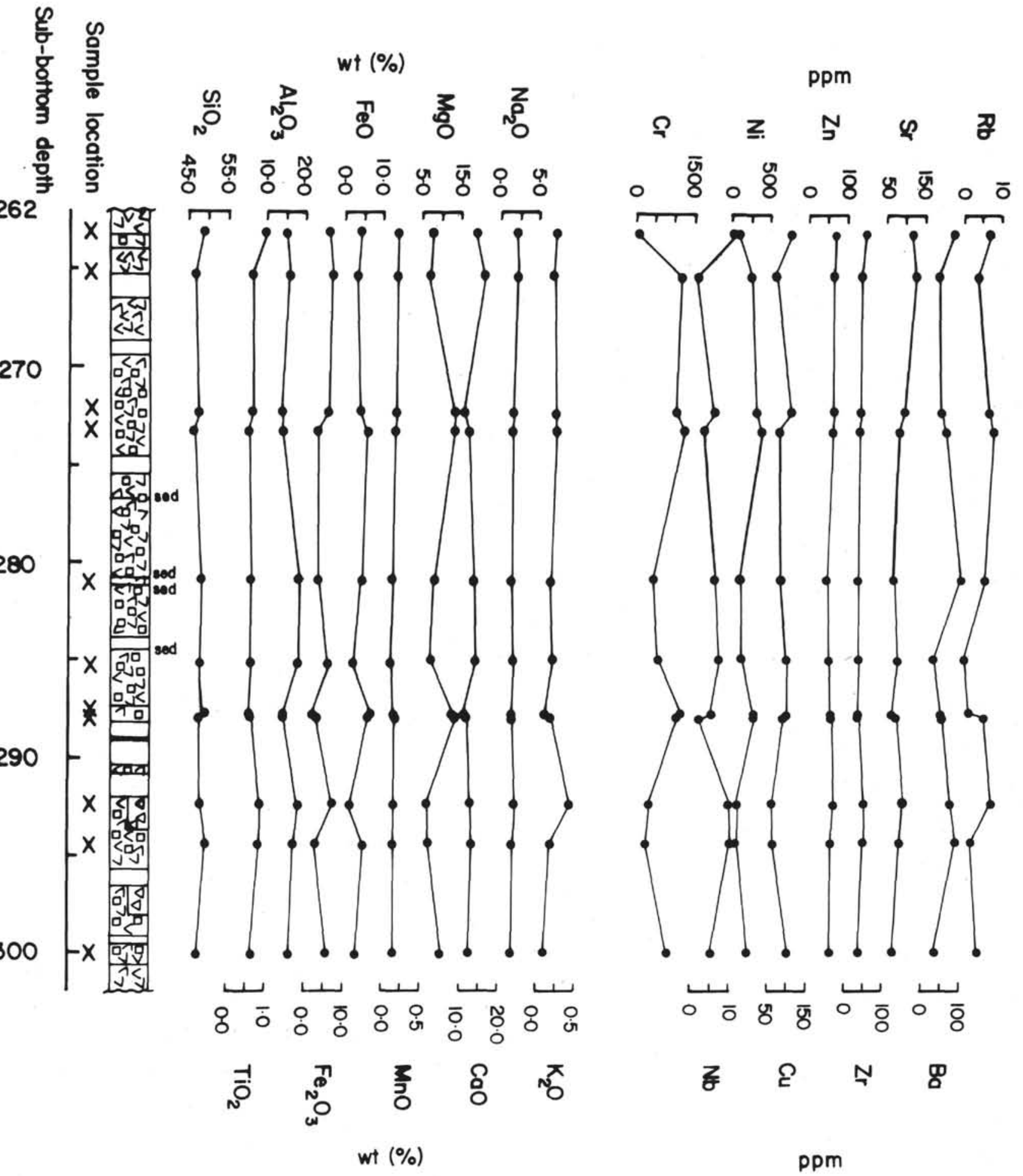

Figure 8. Compositional variation of samples within a small depth interval in Hole 332B. Note the cyclic variation, especially evident from $\mathrm{MgO}, \mathrm{Cr}$, and $\mathrm{Ni}$. The sedimentary units must separate flows and occur within these cyclic variations, indicating that they should be explained as the effects of crystal accumulation in magma chambers prior to eruption. 